\title{
Shear Bond Strength of MDP-Containing Self-Adhesive Resin Cement and Y-TZP Ceramics: Effect of Phosphate Monomer-Containing Primers
}

\author{
Jin-Soo Ahn, ${ }^{1}$ Young-Ah Yi, ${ }^{2}$ Yoon Lee, ${ }^{3}$ and Deog-Gyu Seo ${ }^{4}$ \\ ${ }^{1}$ Department of Dental Biomaterials Science, Dental Research Institute, School of Dentistry, Seoul National University, \\ 101 Daehak-ro, Jongno-gu, Seoul, Republic of Korea \\ ${ }^{2}$ Department of Dentistry, Inje University, Seoul Paik Hospital, Marunae-ro 9, Jung-gu, Seoul, Republic of Korea \\ ${ }^{3}$ Department of Dentistry, Wonju College of Medicine, Yonsei University, 162 Ilsan-dong, Wonju, Republic of Korea \\ ${ }^{4}$ Department of Conservative Dentistry and Dental Research Institute, School of Dentistry, Seoul National University, \\ Seoul, Republic of Korea \\ Correspondence should be addressed to Deog-Gyu Seo; dgseo@snu.ac.kr
}

Received 29 November 2014; Accepted 17 January 2015

Academic Editor: Ahmet U. Güler

Copyright @ 2015 Jin-Soo Ahn et al. This is an open access article distributed under the Creative Commons Attribution License, which permits unrestricted use, distribution, and reproduction in any medium, provided the original work is properly cited.

Purpose. This study was conducted to evaluate the effects of different phosphate monomer-containing primers on the shear bond strength between yttria-tetragonal zirconia polycrystal (Y-TZP) ceramics and MDP-containing self-adhesive resin cement. Materials and Methods. Y-TZP ceramic surfaces were ground flat with \#600-grit SiC paper and divided into six groups $(n=10)$. They were treated as follows: untreated (control), Metal/Zirconia Primer, Z-PRIME Plus, air abrasion, Metal/Zirconia Primer with air abrasion, and Z-PRIME Plus with air abrasion. MDP-containing self-adhesive resin cement was applied to the surface-treated Y-TZP specimens. After thermocycling, a shear bond strength test was performed. The surfaces of the Y-TZP specimens were analyzed under a scanning electron microscope. The bond strength values were statistically analyzed using one-way analysis of variance and the Student-Newman-Keuls multiple comparison test $(P<0.05)$. Results. The Z-PRIME Plus treatment combined with air abrasion produced the highest bond strength, followed by Z-PRIME Plus application, Metal/Zirconia Primer combined with air abrasion, air abrasion alone, and, lastly, Metal/Zirconia Primer application. The control group yielded the lowest results $(P<0.05)$. Conclusion. The application of MDP-containing primer resulted in increased bond strength between Y-TZP ceramics and MDP-containing self-adhesive resin cements.

\section{Introduction}

Yttria-tetragonal zirconia polycrystal (Y-TZP) that is currently used in restorative dentistry contains over $90 \%$ zirconium oxide without silica [1]. Y-TZP provides higher fracture toughness and strength compared to other dental ceramics [2]. Unlike other silica-based ceramics, Y-TZP shows a critical weakness in failing to form reliable and durable bonds due to its resistance to hydrofluoric-acid etching [2].

Predictable cementation is one of the most important factors for achieving clinical success with any restorative material, including Y-TZP [3]. However, the cementation method using mechanical and chemical adhesion remains controversial for Y-TZP, unlike for glass or alumina-based ceramics [4]. Previous studies have proven that air abrasion provides micromechanical bonding and that the use of resin cements that consist of 10-methacryloyloxydecyl dihydrogen phosphate (MDP) strengthens the bonds [5-7].

In order to simplify adhesive cementation procedures, self-adhesive resin cements requiring fewer clinical steps have been developed $[8,9]$. Various self-adhesive resin cements consist of phosphate monomers, including MDP, and manufacturers suggest that clinicians apply self-adhesive cements to Y-TZP without additional Y-TZP primer [10]. However, studies [6,9-11] of the bonding efficiency of phosphate monomers in self-adhesive resin cements to Y-TZP have not 
provided much information on the bonding itself. Thus, it is necessary to evaluate the bond strength between the MDPcontaining self-adhesive resin cement and Y-TZP ceramics when each new phosphate monomer-containing primer is used.

Therefore, the aim of this study was to evaluate the effects of different phosphate monomer-containing primers on the shear bond strength between MDP-containing self-adhesive resin cements and Y-TZP ceramics. The null hypothesis was that zirconia primer application would not influence the bonding strength to Y-TZP ceramics.

\section{Materials and Methods}

2.1. Specimen Preparation. Ceramic disks of $4 \mathrm{~mm}$ thickness, $19 \mathrm{~mm}$ diameter, and $100 \mathrm{~mm}$ height were obtained by sectioning Y-TZP blocks, which were composed of $97 \%$ zirconium dioxide stabilized with a 3\% Yttria-Lava Frame (3M ESPE, St. Paul, MN, USA), using a low-concentration diamond blade (Allied High Tech Productions Inc., CA, USA). Under water cooling, the surfaces of each specimen were ground and polished using silicon carbide abrasives of 600-grit. The Y-TZP ceramic specimens were ultrasonically cleaned for $3 \mathrm{~min}$ in distilled water prior to sintering as the manufacturer's instructions. The specimens were then embedded in polyethylene molds of $19 \mathrm{~mm}$ inner diameter, $21 \mathrm{~mm}$ outer diameter, and $12 \mathrm{~mm}$ height. For cement bonding, a single side of each disk was left exposed.

2.2. Surface Treatments and Bonding Procedure. Depending on the surface treatment method and the resin cement used, 60 specimens were randomly assigned to six groups with 10 specimens per group. The specimens were grouped based on the resin cement used and method of surface treatment. The experimental design and materials used in this study are shown in Tables 1 and 2, respectively. The three groups without air-abrasion treatment were treated with either Metal/Zirconia Primer (Ivoclar Vivadent, Schaan, Liechtenstein) or Z-PRIME Plus (BISCO, Schaumburg, USA) or did not undergo any primer treatment. The three remaining groups were treated with $50 \mu \mathrm{m}$ grain-sized $\mathrm{Al}_{2} \mathrm{O}_{3}$ particles at a standoff distance of $10 \mathrm{~mm}$ and 3.5 bar press for $15 \mathrm{~s}$ using air abrasion. The surface was rinsed for $30 \mathrm{~s}$ and then air-dried for $30 \mathrm{~s}$ after the air abrasion treatment. Either Metal/Zirconia Primer, Z-PRIME Plus treatment, or no primer treatment was performed on the three groups with air abrasion. After being mixed according to the manufacturer's instructions, self-adhesive resin cement (Clearfil SA Luting, Kuraray, Kurashiki, Okayama, Japan) was placed inside a \#5 size gel cap (area $16.8 \mathrm{~mm}^{2}$ ). Each specimen with a gel cap was light-cured from all four sides at $600 \mathrm{~mW} / \mathrm{cm}^{2}$ for $20 \mathrm{~s}$, using an LED curing light unit (Elipar S10, 3M ESPE, St. Paul, MN, USA). At $23 \pm 1^{\circ} \mathrm{C}$, all specimens were left to polymerize further for $1 \mathrm{~h}$. The specimens were then stored in $37^{\circ} \mathrm{C}$ distilled water for $23 \mathrm{~h}$. The specimens were subjected to thermocycling $\left(5-55^{\circ} \mathrm{C}\right.$ for 5000 cycles). The transfer time between baths was $2 \mathrm{~s}$, with a dwelling time of $30 \mathrm{~s}$ at each temperature.
2.3. Bond Strength Test and Surface Analysis. At a $0.5 \mathrm{~mm} / \mathrm{min}$ crosshead speed, the adhesive interface of each specimen was loaded with a jig of the universal testing machine (LF-plus, AMETEK Inc., Largo, FL, USA) until failure occurred. The failure modes were observed under a stereomicroscope $(45 \mathrm{x})$. The resin bonding on the Y-TZP and fractured surfaces was examined using a scanning electron microscope (SEM; S-4700 FESEM, Hitachi, Tokyo, Japan) at $600 \mathrm{x}$ magnification and $10 \mathrm{kV}$ accelerating voltage.

2.4. Statistical Analysis. For data analysis, the R programming language ( $\mathrm{R}$ Foundation for Statistical Computing, Vienna, Austria) [12] was used. The normality of the data and equality of the variance were confirmed. A one-way analysis of variance (ANOVA) and Student-Newman-Keuls multiple comparison test were carried out. The mean difference was considered significant at the level of $P<0.05$.

\section{Results}

The means and standard deviations for shear bond strength of all groups are presented in Table 3. One-way ANOVA was used to calculate the statistical significance for the different surface treatments $(P<0.05)$. Air abrasion and the use of Z-PRIME Plus were more effective than the control group treatment. The group treated with Z-PRIME Plus after air abrasion showed the best results.

Figure 1 shows representative SEM images (magnification 600x) for Clearfil SA Luting cement residues on the contact area of the Y-TZP specimens. The failure mode distribution for all samples is shown Figure 2.

\section{Discussion}

This study investigated the effects of different phosphate monomer-containing primers on the shear bond strength between MDP-containing self-adhesive resin cements and YTZP ceramics.

The null hypothesis was rejected for the case of MDP as the effective functional monomer in this experiment, and the untreated Y-TZP surfaces showed the lowest bond strengths. High incidence of adhesive failure was observed, leaving the Y-TZP surfaces free of any luting material remnants, which explains the significantly lower bond strength between the self-adhesive resin cement and the untreated Y-TZP surfaces in the control group. This result may be caused by the poor chemical interaction at the interface between the components, at the interface between the MDP component of the Clearfil SA Luting cement and the hydroxyl groups of the Y-TZP ceramics. Other studies $[5,6,13,14]$ have also reported low bond strength when conventional resin cements are used on untreated Y-TZP ceramic surfaces.

Our results indicate that bond strength can be affected by treatment with primer containing MDP, as well as by conventional methods including air abrasion. The bond strength was influenced greatly by $50 \mu \mathrm{m}$ sized particle air abrasion regardless of the zirconia primer pretreatment. This result is consistent with previous studies $[4-6,15]$. The air abrasion 


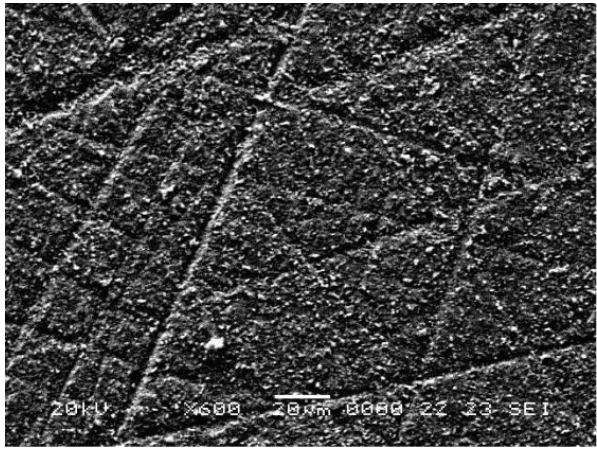

(a)

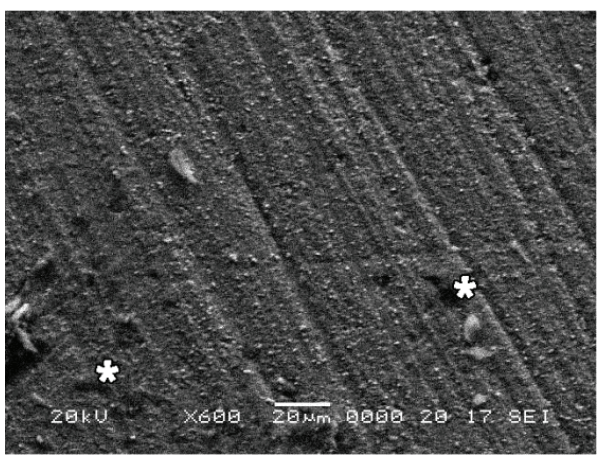

(c)

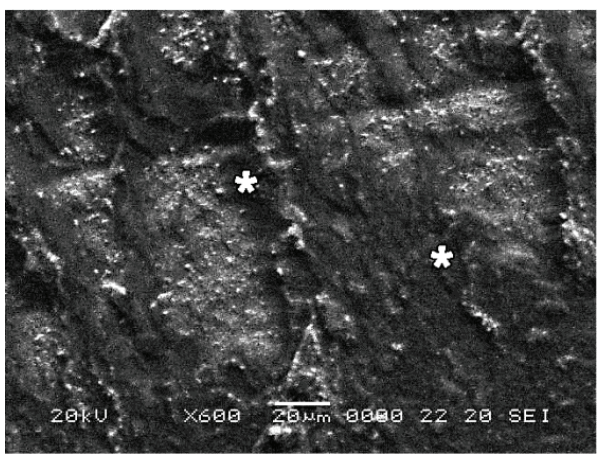

(e)

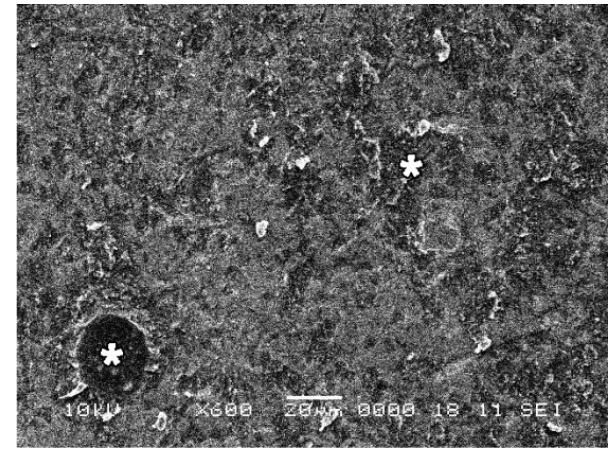

(b)

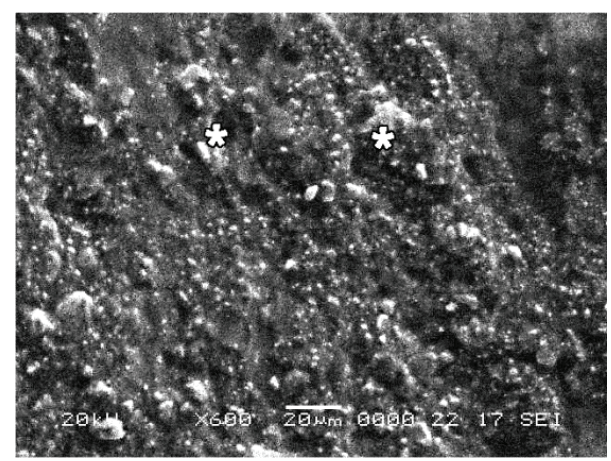

(d)

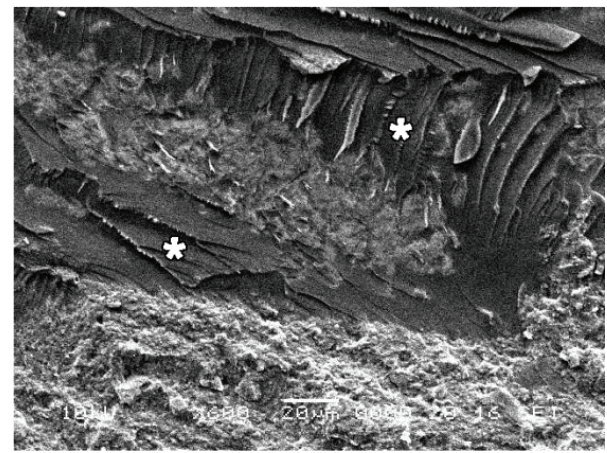

(f)

FIGURE 1: Representative scanning electron microscope images (600x original magnification) of Y-TZP ceramic specimens debonded after cementation with Clearfil SA Luting. (a) Polished Y-TZP; (b) airborne abrasion with $50 \mu \mathrm{m}$ grain-sized $\mathrm{Al}_{2} \mathrm{O}_{3}$; (c) Metal/Zirconia Primer, a zirconia primer applied on polished Y-TZP; (d) Metal/Zirconia Primer, a zirconia primer applied on Y-TZP after airborne abrasion; (e) ZPRIME Plus, a zirconia primer applied on polished Y-TZP; and (f) Z-PRIME Plus, a zirconia primer applied on Y-TZP after airborne abrasion. The regions marked with white stars indicate the remaining resin cements.

TABLE 1: Experimental design for each surface treatment on Y-TZP specimens in this study.

\begin{tabular}{|c|c|c|c|c|c|}
\hline \multicolumn{6}{|c|}{ Y-TZP blocks (ground with 600-grit silicon carbide abrasive paper and sintered) } \\
\hline \multicolumn{3}{|c|}{$\downarrow$} & \multicolumn{3}{|c|}{$\downarrow$} \\
\hline \multicolumn{3}{|c|}{ No air abrasion } & \multicolumn{3}{|c|}{ Air abrasion } \\
\hline \multicolumn{3}{|c|}{$\downarrow$} & \multicolumn{3}{|c|}{$\downarrow$} \\
\hline \multirow[t]{2}{*}{ None } & Metal/Zirconia Primer & Z-PRIME Plus & None & Metal/Zirconia Primer & Z-PRIME Plus \\
\hline & $\downarrow$ & & & $\downarrow$ & \\
\hline \multicolumn{6}{|c|}{$\begin{array}{l}\text { Bonding with Clearfil SA Luting cement (Kuraray, Kurashiki, Okayama, Japan) } \\
5000 \text { thermal cycles between } 5 \text { and } 55^{\circ} \mathrm{C} \text {, shear bond test }(n=10)\end{array}$} \\
\hline
\end{tabular}


TABLE 2: Characteristics of experimental materials.

\begin{tabular}{lclc}
\hline Materials & Brand & Product & Manufacturer \\
\hline Y-TZP & LAVA & $\begin{array}{l}97 \% \text { zirconium dioxide stabilized with 3\% Yttria-Lava } \\
\text { frame }\end{array}$ & $\begin{array}{c}\text { 3M ESPE, St. Paul, MN, } \\
\text { USA }\end{array}$ \\
\hline \multirow{2}{*}{ Primer } & Z-PRIME Plus & HEMA, BPDM, ethanol, and MDP & $\begin{array}{c}\text { Bisco Inc., Schaumburg, IL, } \\
\text { USA }\end{array}$ \\
& $\begin{array}{l}\text { Metal/Zirconia } \\
\text { Primer }\end{array}$ & $\begin{array}{l}\text { Dimethacrylate, tertiary butyl alcohol, methyl isobutyl } \\
\text { ketone, phosphonic acid acrylate, and benzoyl peroxide } \\
\text { containing primer }\end{array}$ & $\begin{array}{c}\text { Ivoclar Vivadent, Schaan, } \\
\text { Liechtenstein }\end{array}$ \\
\hline Resin cement & Clearfil SA Luting & $\begin{array}{l}\text { Bis-GMA, TEGDMA, MDP, barium glass, silica, and } \\
\text { sodium fluoride }\end{array}$ & $\begin{array}{c}\text { Kuraray, Kurashiki, } \\
\text { Okayama, Japan }\end{array}$ \\
\hline
\end{tabular}

HEMA: hydroxyethyl methacrylate, BPDM: biphenyl dimethacrylate, MDP: 10-methacryloyloxydecyl dihydrogen phosphate, MPS: 3-methacryloxyprophyltrimethoxy silane, Bis-GMA: bisphenol A-glycidyl methacrylate, and TEGDMA: triethylene glycol dimethacrylate.

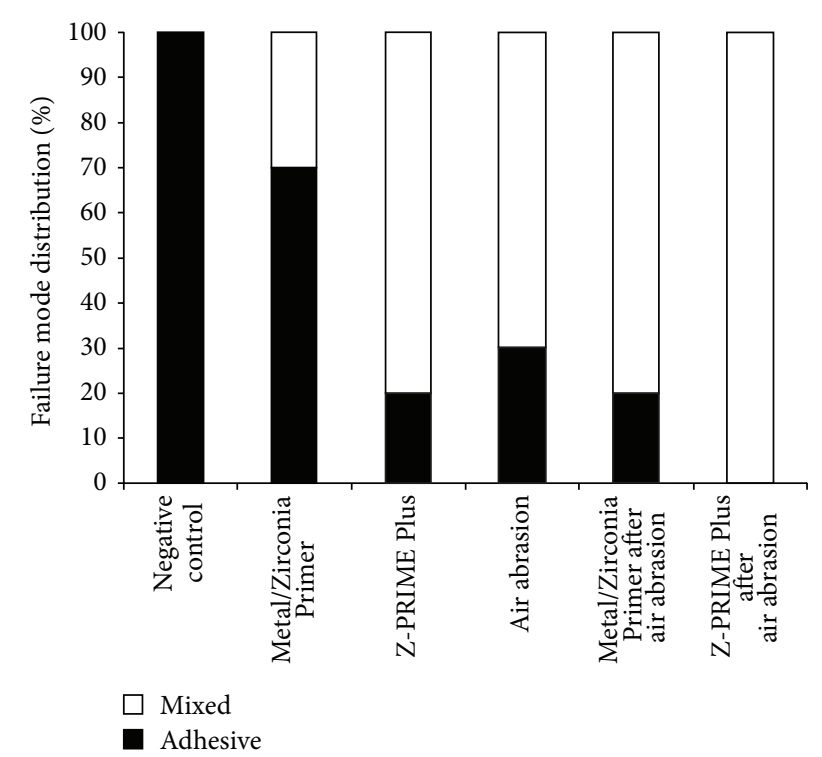

FIGURE 2: Distribution of failure modes after 10,000 thermocycles.

TABLE 3: Means and standard deviations of the shear bond strength $(\mathrm{MPa})$ of the samples with Clearfil SA Luting cement and different surface treatments on Y-TZP $(n=10)$.

\begin{tabular}{lcc}
\hline \multirow{2}{*}{ Priming conditions } & \multicolumn{2}{c}{ Surface conditions } \\
& No air abrasion (polished) & Air abrasion \\
\hline None & $4.61(1.13)^{\mathrm{A}}$ & $9.84(2.36)^{\mathrm{B}}$ \\
Metal/Zirconia Primer & $5.41(1.66)^{\mathrm{A}}$ & $10.00(2.29)^{\mathrm{B}}$ \\
Z-PRIME Plus & $10.72(1.70)^{\mathrm{B}}$ & $15.23(1.97)^{\mathrm{C}}$ \\
\hline
\end{tabular}

Different superscripts indicate a statistical difference $(P<0.05)$, and identical superscripts indicate no statistical difference in the designated group after the Student-Newman-Keuls multiple comparison test.

method is thought to assist in the progress of resin cement flow into microretentions due to increased roughness and surface energy, which create micromechanical interlocking between the resin cements and Y-TZP $[6,16]$. Moreover, air abrasion may generate hydroxyl groups on the Y-TZP surfaces, facilitating the chemical reaction with phosphate monomers $[17,18]$.
The results of this study show that the MDP containing Z-PRIME Plus promotes durable bonding to Y-TZP. Even though the self-adhesive resin cement included MDP, its functional monomer properties in terms of the amount and flow seemed insufficient to increase the Y-TZP adhesion ability without any pretreatment $[6,19]$. Therefore, MDP functional monomers need to be applied to Y-TZP surfaces even if the self-adhesive resin cement contains such monomers. This interpretation is consistent with the results of previous studies $[5,6,20,21]$. The phosphate ester group of the adhesive monomers and zirconia oxides chemically creates direct bonds [7, 22, 23]. MDP has bifunctional ends that consist of long organic hydrophobic chain molecules. Hydrophilic phosphate ester groups at one end bond strongly to Y-TZP, and vinyl groups react with the monomers of the resin cement at the other end [20,24].

In the present study, only the MDP-based product, ZPRIME Plus, had a significantly higher bond strength than did the phosphonic acid-based Metal/Zirconia Primer. The reason is probably that MDP was more effective than phosphonic acid acrylate in Y-TZP surface treatment, though the same phosphate monomer was included in both products [22]. In other studies, MDP-based primers were proven to have higher bond strengths on Y-TZP compared to other primers $[7,21,22,25]$.

It is notable that adhesive failure can be observed in the control group images, whereas the specimens treated with air abrasion, Metal/Zirconia Primer, Z-PRIME Plus, and air abrasion in combination with Z-PRIME Plus presented mixed failures with resin cement. The resin cement remnants can be seen to a relative degree (Figures 1(a)-1(f)). Figure 1(f) shows a unique ridged appearance, with more resin cement residues in the group with a combination of air abrasion and Z-PRIME Plus application.

The highest bond strength was achieved through the combination of air-abrasion treatment and MDP-based product application. This result may be due to the air-abrasion treatment enhancing the surface wettability and the MDPcontaining primer increasing the bond strength, thus improving the chemical affinity. In this group, all specimens indicated mixed fracture patterns, which may be due to the combined effects of the increased contact area with the YTZP ceramic surface and the improved chemical interaction 
with the MDP monomer in Z-PRIME Plus [6, 7]. The combination of MDP-containing primer application and airabrasion treatment is recommended to achieve strong and durable bonds to Y-TZP using self-adhesive resin cements containing MDP monomers.

\section{Conclusion}

Within the limitations of this study, the following can be concluded.

(1) The application of MDP-containing self-adhesive resin cement without pretreatment was not sufficient to improve the bond strength to an untreated Y-TZP surface.

(2) MDP-containing primer application seems to be a reliable method for increasing the bond strength between Y-TZP ceramics and MDP-containing selfadhesive resin cements.

\section{Conflict of Interests}

The authors declare that they have no conflict of interests.

\section{Acknowledgment}

This work was supported by the Basic Science Research Program through the National Research Foundation of Korea (NRF), funded by the Ministry of Education, Science and Technology (2010-0005090, 2012-009268).

\section{References}

[1] C. Piconi and G. Maccauro, "Zirconia as a ceramic biomaterial," Biomaterials, vol. 20, no. 1, pp. 1-25, 1999.

[2] A. N. Cavalcanti, R. M. Foxton, T. F. Watson, M. T. Oliveira, M. Giannini, and G. M. Marchi, "Bond strength of resin cements to a zirconia ceramic with different surface treatments," Operative Dentistry, vol. 34, no. 3, pp. 280-287, 2009.

[3] P. Magne, M. P. G. Paranhos, and L. H. Burnett Jr., "New zirconia primer improves bond strength of resin-based cements," Dental Materials, vol. 26, no. 4, pp. 345-352, 2010.

[4] J.-Y. Yun, S.-R. Ha, J.-B. Lee, and S.-H. Kim, "Effect of sandblasting and various metal primers on the shear bond strength of resin cement to Y-TZP ceramic," Dental Materials, vol. 26, no. 7, pp. 650-658, 2010.

[5] Y.-J. Shin, Y.-A. Yi, J. Kim et al., "Evaluation of the shear bond strength of resin cement to Y-TZP ceramic after different surface treatments," Scanning, vol. 36, no. 5, pp. 479-486, 2014.

[6] Y. A. Yi, J. S. Ahn, and Y. J. Park, "The effect of sandblasting and different primers on shear bond strength between yttriatetragonal zirconia polycrystal ceramic and a self-adhesive resin cement," Operative Dentistry, vol. 40, no. 1, pp. 63-71, 2015.

[7] F. Lehmann and M. Kern, "Durability of resin bonding to zirconia ceramic using different primers," The Journal of Adhesive Dentistry, vol. 11, no. 6, pp. 479-483, 2009.

[8] T. R. Aguiar, M. di Francescantonio, G. M. B. Ambrosano, and M. Giannini, "Effect of curing mode on bond strength of selfadhesive resin luting cements to dentin," Journal of Biomedical
Materials Research-Part B Applied Biomaterials, vol. 93, no. 1, pp. 122-127, 2010.

[9] W. F. de Sá Barbosa, T. R. Aguiar, M. D. Francescantonio, A. N. Cavalcanti, M. T. de Oliveira, and M. Giannini, "Effect of water storage on bond strength of self-adhesive resin cements to zirconium oxide ceramic," The Journal of Adhesive Dentistry, vol. 15, no. 2, pp. 145-150, 2013.

[10] D.-G. Seo, "Zirconia surface treatment for successful bonding," Restorative Dentistry \& Endodontics, vol. 39, no. 4, p. 333, 2014.

[11] M. B. Blatz, J.-H. Phark, F. Ozer et al., "In vitro comparative bond strength of contemporary self-adhesive resin cements to zirconium oxide ceramic with and without air-particle abrasion," Clinical Oral Investigations, vol. 14, no. 2, pp. 187-192, 2010.

[12] R Development Core Team, R: A Language and Environment for Statistical Computing, R Foundation for Statistical Computing, Vienna, Austria, 2010.

[13] M. Wolfart, F. Lehmann, S. Wolfart, and M. Kern, "Durability of the resin bond strength to zirconia ceramic after using different surface conditioning methods," Dental Materials, vol. 23, no. 1, pp. 45-50, 2007.

[14] S. Kasraei, L. Rezaei-Soufi, B. Heidari, and F. Vafaee, "Bond strength of resin cement to $\mathrm{CO}_{2}$ and Er:YAG laser-treated zirconia ceramic," Restorative Dentistry \& Endodontics, vol. 39, no. 4, pp. 296-302, 2014.

[15] L. F. Valandro, M. Özcan, M. C. Bottino, M. A. Bottino, R. Scotti, and A. D. Bona, "Bond strength of a resin cement to highalumina and zirconia-reinforced ceramics: the effect of surface conditioning," Journal of Adhesive Dentistry, vol. 8, no. 3, pp. 175-181, 2006.

[16] M. Kern and S. M. Wegner, "Bonding to zirconia ceramic: adhesion methods and their durability, Dental Materials, vol. 14, no. 1, pp. 64-71, 1998.

[17] L. Miragaya, L. C. Maia, C. E. Sabrosa, M. F. de Goes, and E. M. da Silva, "Evaluation of self-adhesive resin cement bond strength to yttria-stabilized zirconia ceramic (Y-TZP) using four surface treatments," The Journal of Adhesive Dentistry, vol. 13, no. 5, pp. 473-480, 2011.

[18] S. P. Passos, L. G. May, D. C. Barca, M. Özcan, M. A. Bottino, and L. F. Valandro, "Adhesive quality of self-adhesive and conventional adhesive resin cement to Y-TZP ceramic before and after aging conditions," Operative Dentistry, vol. 35, no. 6, pp. 689-696, 2010.

[19] R. C. de Oyagüe, F. Monticelli, M. Toledano, E. Osorio, M. Ferrari, and R. Osorio, "Influence of surface treatments and resin cement selection on bonding to densely-sintered zirconiumoxide ceramic," Dental Materials, vol. 25, no. 2, pp. 172-179, 2009.

[20] H. Koizumi, D. Nakayama, F. Komine, M. B. Blatz, and H. Matsumura, "Bonding of resin-based luting cements to zirconia with and without the use of ceramic priming agents," The Journal of Adhesive Dentistry, vol. 14, no. 4, pp. 385-392, 2012.

[21] D. Nakayama, H. Koizumi, F. Komine, M. B. Blatz, N. Tanoue, and $\mathrm{H}$. Matsumura, "Adhesive bonding of zirconia with singleliquid acidic primers and a tri-n-butylborane initiated acrylic resin," The Journal of Adhesive Dentistry, vol. 12, no. 4, pp. 305310, 2010.

[22] L. Chen, B. I. N. Suh, D. Brown, and X. Chen, "Bonding of primed zirconia ceramics: evidence of chemical bonding and improved bond strengths," The American Journal of Dentistry, vol. 25, no. 2, pp. 103-108, 2012. 
[23] C. Chen, H. Xie, X. Song, M. F. Burrow, G. Chen, and F. Zhang, "Evaluation of a commercial primer for bonding of zirconia to two different resin composite cements," The Journal of Adhesive Dentistry, vol. 16, no. 2, pp. 169-176, 2014.

[24] J.-L. Román-Rodríguez, A. Fons-Font, V. Amigó-Borrás et al., "Bond strength of selected composite resin-cements to zirconium-oxide ceramic," Medicina Oral, Patologia Oral y Cirugia Bucal, vol. 18, no. 1, pp. el15-e123, 2013.

[25] K. Kobayashi, M. B. Blatz, A. Saito, H. Koizumi, and H. Matsumura, "Influence of priming agents on the short-term bond strength of an indirect composite veneering material to zirconium dioxide ceramic," Quintessence International, vol. 40, no. 7, pp. 545-551, 2009. 

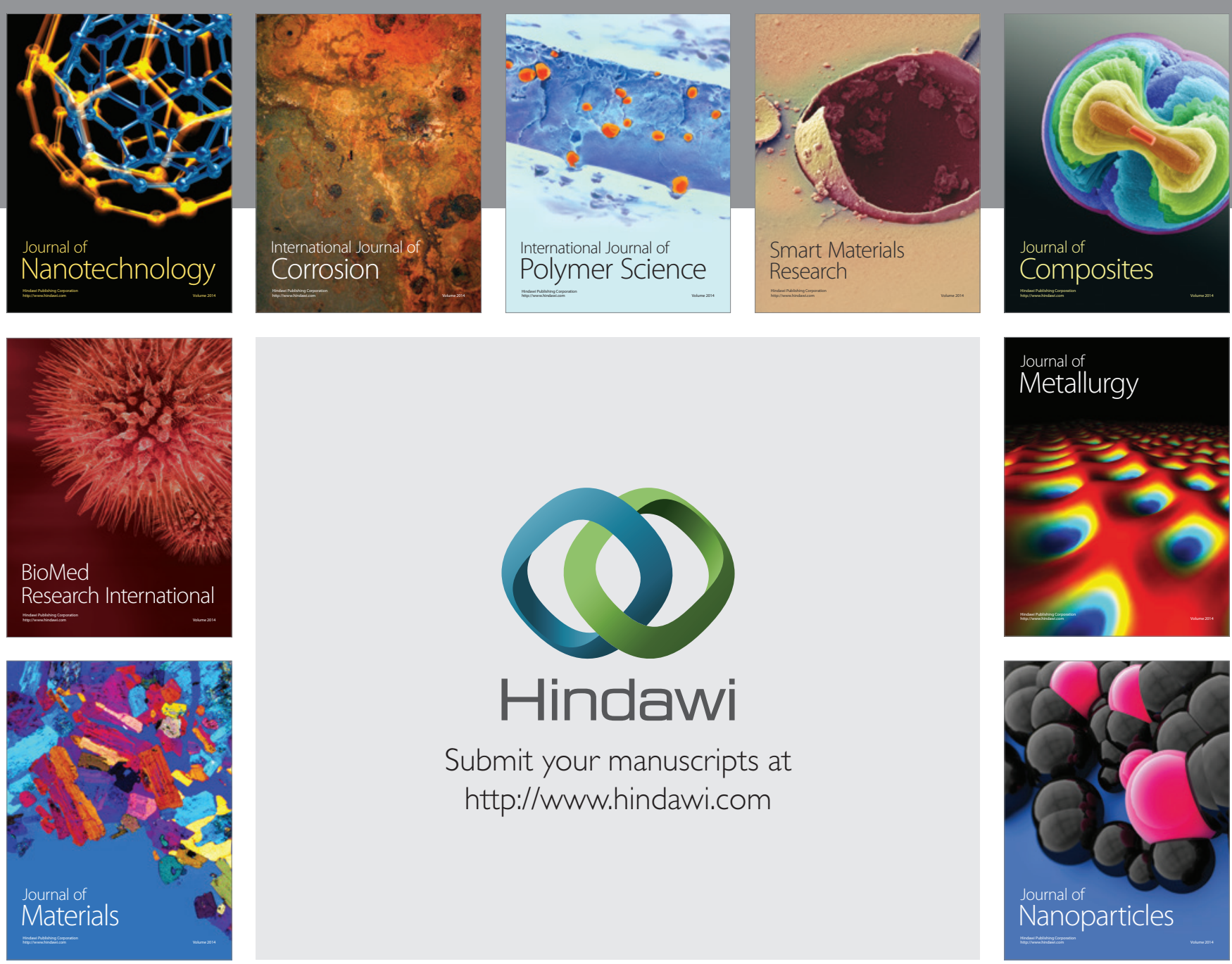

Submit your manuscripts at http://www.hindawi.com
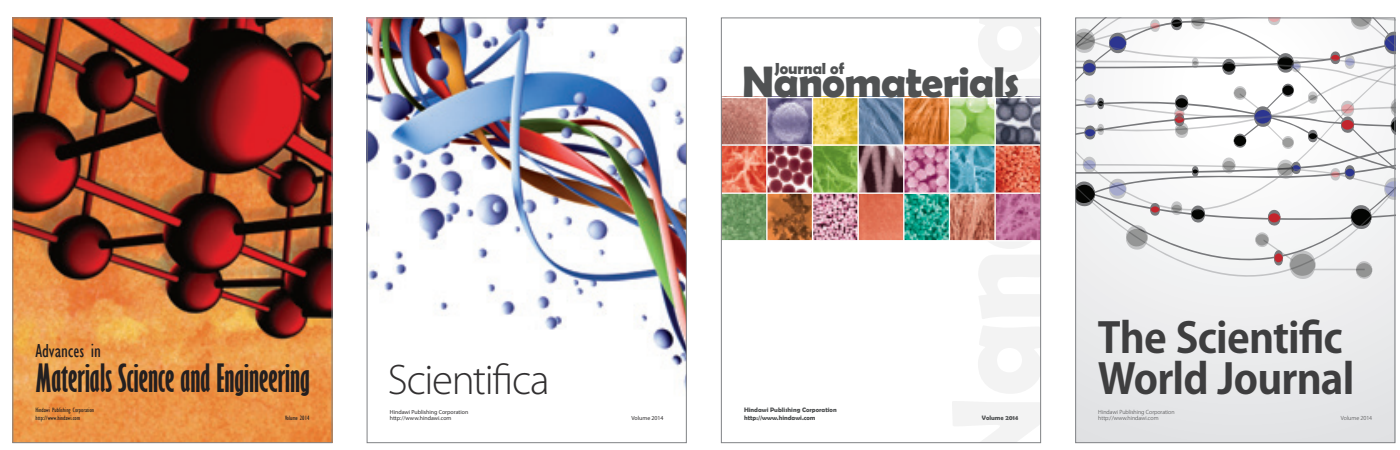

\section{The Scientific World Journal}
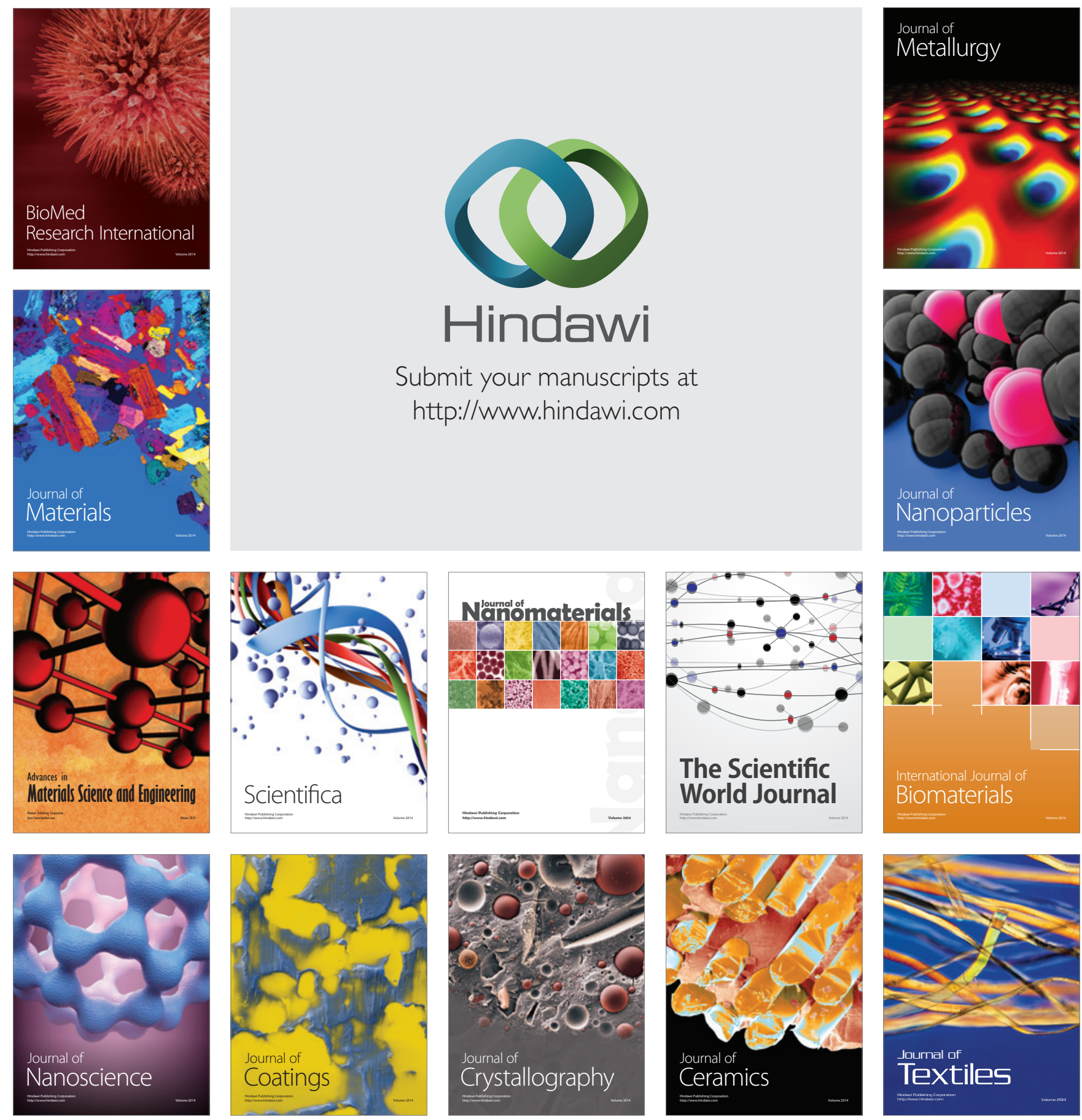